\title{
In Vitro Antileishmanial Activity of Resveratrol Originates from its Cytotoxic Potential against Host Cells
}

Authors

Affiliation
Ina Katharina Lucas, Herbert Kolodziej

Freie Universität Berlin, Institute of Pharmacy, Pharmaceutical Biology, Berlin, Germany

\author{
Key words \\ - Leishmania major GFP \\ - resveratrol \\ - macrophages \\ - antileishmanial activity \\ - nitric oxide \\ - cytotoxicity
}

\section{Abstract \\ $\nabla$}

In addition to a range of beneficial pharmacological activities, resveratrol is recently reported to have potential antileishmanial activities in vitro. The present study was conducted to evaluate the effect of resveratrol on promastigotes and amastigotes of transgenic Leishmania major expressing green fluorescent protein in comparison with its direct cytotoxic effects on host cells (bone marrow-derived and J774-G8 macrophages, respectively). As assessed by FACS analysis, resveratrol showed moderate antipromastigote activity at $<35 \mu \mathrm{g} / \mathrm{mL}(153.2 \mu \mathrm{M})$ and promising effects at higher sample concentrations. In contrast, the green fluorescent protein signal as a measure of the intracellular parasites' viability was reduced in a concentration-dependent manner. Resveratrol strongly inhibited NO production, but did not display direct NO-scavenging activity in sodium nitroprusside solution. Western blotting indicated that resveratrol reduced recombinant inter-

\section{Introduction}

$\nabla$

All species of the genus Leishmania are obligate intracellular parasites of the monocyte-macrophage system. Leishmaniasis is a prevalent spectral disease in most developing countries, with clinical manifestations that depend not only on the protozoan species initiating infection but also on the general health as well as genetic potential and acute predisposition of the host defense system. In recent years, human populations of the developed world were also notably affected, probably compounded by facilitated international travel, carelessness of people, and improved climatic conditions for both the insect vector (sandflies) and the parasites due to global warming [1]. Despite the major adverse impact of Leishmania parasites on human populations throughout the feron- $\gamma /$ LPS-induced expression of iNOS protein. Microscopic studies, MTT evaluation, and FACS analysis showed significant cytotoxic effects on host cells in a concentration-dependent manner. This finding suggests that the in vitro antileishmanial activity of resveratrol is due to cytotoxic effects on host cells rather than attributable to a specific antiparasitic potential.

\section{Abbreviations \\ $\nabla$}

ВММФ: bone marrow-derived macrophages

PI: $\quad$ propidium iodide

GFP: $\quad$ green fluorescent protein

FCS: $\quad$ fetal calf serum

SNP: $\quad$ sodium nitroprusside

rIFN: recombinant interferon

Supporting information available online at http://www.thieme-connect.de/ejournals/toc/ plantamedica

world and the increasingly observed partial resistance to antimonials, the first choice of drugs, only limited advances in the therapy of leishmaniasis have been achieved since the introduction of antimonials in the chemotherapy of these parasitic infections. Given the limitations of the current treatments for leishmaniasis reflected by severely toxic side effects and the annual incidence of about 2 million new cases [2], there is clearly an urgent need for the development of new drugs.

The use of medicinal plants for the treatment of parasitic diseases is well known and documented since hundreds of years. Regarding leishmaniasis, newly established drug formulations and vaccine development are of little practical use in underdeveloped territories due to high costs. It is therefore not surprising that herbal medicines are commonplace in endemic countries and that 
most of their populations still rely on the use of plants as low-cost medication to treat infectious conditions. Advances in the research of natural plant products for the treatment of leishmaniasis have repeatedly been reviewed [3-7]. Many natural products did not progress through preclinical studies because of, e.g., low bioavailability. Another important consideration concerns the economics. The identification of an effectively antileishmanial herbal or even dietary source or natural product well tolerated in therapeutic doses that is readily available in endemic areas would therefore considerably contribute to the health care of people living at risk of leishmaniasis.

The stilbene resveratrol occurs in low amounts in various dietary and herbal sources including grapes, cranberries, blueberries, peanuts, Veratrum grandiflorum, Rheum rhaponticum, and Polygonum cuspidatum [8]. Much interest in this secondary metabolite has been heightened by reports of a broad spectrum of health-promoting properties [8], ranging from putative cancer chemoprevention [9], beneficial effects on cardiovascular disease [10] and ischemic injury, enhanced stress resistance, extension of the lifespan of various organisms, a promising role in diabetes to anti-inflammatory effects [11]. In contrast, little is hitherto known about antimicrobial or antiparasitic activities of resveratrol. Following some documented clues against dermatophytes, parasitic fungi and viruses, the antileishmanial potential of resveratrol has been recently evaluated for the first time using Leishmania major as a test organism [12]. Based on microscopic examinations, resveratrol was found to exhibit pronounced activities against extracellular promastigotes and intracellular amastigotes, while revealing no adverse effects on murine macrophage J774 host cells. The mode of action, however, remains to be investigated. This and the limited number of stilbenes tested to date prompted the present study in the continuation of our work focussing on polyphenols as potential antileishmanial agents. Here, we report on the antileishmanial activity of resveratrol against promastigotes and amastigotes of transgenic L. major GFP in comparison with their direct cytotoxic effects on two murine macrophage cell cultures, ВМMФ and J774-G8, as their host cells. The experimental FACS-based protocol allowed the quantification of intracellular parasite survival and, in parallel, the cell viability of individual host cells [13]. In addition, cytotoxic effects on macrophage cell lines were measured by the MTT assay and concurrent microscopic examinations for comparison.

\section{Materials and Methods}

$\nabla$

\section{Chemicals}

Amphotericin B, resveratrol, and DMSO were purchased from Sigma-Aldrich. All chemicals were free of LPS.

\section{Cell culture}

The murine macrophage J774-G8 cell line, obtained from Bernhard Nocht-Institut, was cultured in RPMI 1640 medium (Gibco Invitrogen) supplemented with HEPES (10 mM; Biochrom AG), Na-pyruvat (1 mM; Sigma-Aldrich Chemie), penicillin (100 U/ $\mathrm{mL}$; PAA Laboratories), streptomycin $(100 \mu \mathrm{g} / \mathrm{mL}$; PAA Laboratories), and 5 or $10 \%$ heat-inactivated FCS at $37^{\circ} \mathrm{C}$ in a humidified atmosphere with $5 \% \mathrm{CO}_{2}$. The culture medium is herein designated R5 or R10.

\section{Parasites}

GFP transfected L. major parasites (L. major GFP, strain LT 252, clone CC-1pXG-GFP), stable under the influence of geneticin [14], were kindly provided by S.M. Beverley (Department of Molecular Biology, Washington University School of Medicine, St. Louis, MO, USA). The parasites were cultured in Leishmania growth medium consisting of R5 and 10\% МФ-conditioned medium at $25^{\circ} \mathrm{C}$ in a humidified atmosphere with $5 \% \mathrm{CO}_{2}$. MФ-conditioned medium consisted of the cell-free supernatant of 4- to 6day-old murine MФ cultured in RPMI 1640 supplemented with $10 \%$ FCS and hemin $(0.25 \% \mathrm{v} / \mathrm{v}$ solution B of Hosmen II medium) [15].

\section{Mice}

Six- to 12-week-old female C57 BL/6 mice were supplied by Zentrale Versuchstierzucht, Federal Institute for Risk Assessment (BfR), Berlin, Germany. Animal care and the experimental procedures were in accordance with the institutional guidelines and German law. The animal experiments were approved by the Landesamt für Gesundheit und Soziales, Berlin on April 27, 2004 under the number $01707 / 04$.

\section{ВМММФ}

Mice were killed by cervical dislocation and bone marrow was obtained by flushing the femura and tibia with ice-cold $\mathrm{Ca}^{2+}$ and $\mathrm{Mg}^{2+}$-free PBS. ВМMФ were produced as described previously $[12,16]$. For harvesting, the medium was replaced by cold PBS to remove most nonadherent cells and debris. ВMM $\Phi$ were chilled to $4^{\circ} \mathrm{C}$ for $1 \mathrm{~h}$, rinsed off the plastic and washed by centrifugation $\left(200 \times \mathrm{g}, 10 \mathrm{~min}, 4^{\circ} \mathrm{C}\right)$. The viable cells (trypan-blue exclusion) were counted using a Neubauer Chamber and kept in the dark at $4^{\circ} \mathrm{C}$ until use.

\section{In vitro infection}

ВMMФ and J774-G8 cells, respectively, were infected with parasites as described previously [12]. Briefly, macrophage cultures $\left(1 \times 10^{7}\right.$ cells $/ \mathrm{mL}$ R10) and L. major GFP promastigotes $\left(8 \times 10^{7}\right.$ parasites/mL R10) were combined, giving an approximate macrophage/parasite ratio of $1: 8$. The suspension was centrifuged $\left(250 \times \mathrm{g}, 5 \mathrm{~min}, 4^{\circ} \mathrm{C}\right)$ to facilitate cell contact and incubated at $37^{\circ} \mathrm{C}$ for $2-3 \mathrm{~h}$. Subsequently, the cells were centrifuged $(200 \times$ g, $10 \mathrm{~min}, 4^{\circ} \mathrm{C}$ ), and the supernatant discarded and replaced by ice-cold PBS.

After washing to remove remaining extracellular parasites, the pellet was resuspended in R10 at $1 \times 10^{6} \mathrm{BMM} \Phi / \mathrm{mL}$ medium, transferred into $5-\mathrm{mL}$ sterile polystyrene round-bottom tubes (Falcon) and incubated for $24 \mathrm{~h}$ at $37^{\circ} \mathrm{C}$ to allow internalized L. major parasites to transform into amastigotes. Aliquots of infected macrophages were treated with different concentrations of resveratrol for $48 \mathrm{~h}$, washed carefully, centrifuged $(200 \times \mathrm{g}$, $10 \mathrm{~min}, 4^{\circ} \mathrm{C}$ ), resuspended in $300 \mu \mathrm{L}$ ice-cold PBS and stored on ice until use.

\section{Flow cytometric measurements of infected macrophages}

Information on the rate of infection was obtained by comparing the GFP signal with that of noninfected cells. After treatment with resveratrol, cells were resuspended in $300 \mu \mathrm{L}$ of PBS and stored on ice to facilitate the detachment of the remaining adherent cells. To discriminate dead from living cells, PI (Sigma-Aldrich) solution was added ca. $30 \mathrm{~s}$ before the FACS measurement, giving a final concentration of $0.33 \mu \mathrm{g}$ PI/tube. A total amount of 
20000 events were counted using a FACSCalibur cytometer (Becton Dickinson) and FlowJo software (FlowJo v8.8.4) with the following instrument settings: forward scatter (E-1, linear mode; threshold 52 ), side scatter ( $344 \mathrm{~V}$, linear mode), fluorescence 1 ( $540 \mathrm{~V}, \log$ mode), and fluorescence 3 ( $580 \mathrm{~V}, \log$ mode).

\section{Microscopic examination of infected macrophages}

Macrophage suspensions ( $5 \times 10^{4}$ cells/ $100 \mu \mathrm{L}$ R5) were plated on sterile $13-\mathrm{mm}$ cover slips and the cells were left to rest for $2 \mathrm{~h}$ to allow to adhere. Medium was carefully removed, and $500 \mu \mathrm{L}$ of L. major GFP cultures added (ratio of macrophages/parasites $1: 8)$ and incubated for $2 \mathrm{~h}$ at $37^{\circ} \mathrm{C}, 5 \% \mathrm{CO}_{2}$. Culture medium (R5) was aspirated, and cover slips were carefully rinsed two times with warm medium to remove extracellular parasites [17]. After $24 \mathrm{~h}$, the medium was replaced by different concentrations of resveratrol and incubated for $48 \mathrm{~h}$ in a humidified atmosphere with $5 \% \mathrm{CO}_{2}$. Finally, the incubations were washed twice in warm PBS. Infected cells as well as uninfected and untreated cells were included as controls in each experiment.

Following Diff-Quik ${ }^{\circledR}$ staining, cover slips were placed on glass slides and sealed with a solution of polymer in xylene (Entellan ${ }^{\circledR}$; Merck). Cell morphology was examined microscopically (conventional microscope: Axioskop 2; Carl Zeiss).

\section{Assay for cytotoxicity of resveratrol against macrophages (MTT assay)}

The direct effect of resveratrol on the viability of macrophages was assessed by monitoring the MTT [3-(4,5-dimethylthiazol-2yl)-2,5 diphenyl tetrazolium bromide] metabolism after a 48-h culture period. Noninfected macrophages $\left(1 \times 10^{5} \mathrm{BMM \Phi /well;}\right.$ $2.5 \times 10^{4} \mathrm{~J} 774-\mathrm{G} 8 /$ well) were seeded into 96-well plates and exposed to different concentrations of resveratrol. Following incubation at $37^{\circ} \mathrm{C}$, MTT $(20 \mu \mathrm{L} /$ well of a $5 \mathrm{mg} / \mathrm{mL}$ stock solution) was added to each well. After $6 \mathrm{~h}$, the MTT processing was stopped, cells lysed and formazan crystals solubilized by adding acidified SDS (20\%; $50 \mu \mathrm{L} /$ well) $[16,18]$. The relative amount of formazan/well produced by viable cells was determined spectrophotometrically at $570 \mathrm{~nm}$ by blanking against an appropriate control. Absorbance was measured using a Tecan Infinite M 200 Pro plate reader. The experiments were performed at least in triplicate and data are expressed as mean \pm standard deviation.

\section{Griess assay for NO production by activated J774-G8 macrophages}

Cells were seeded at $5 \times 10^{4} / \mathrm{mL}$ R5 medium in 96-well microtiter plates. The medium was replaced by fresh medium containing different concentrations of resveratrol (4.4-43.8 $\mu \mathrm{M})$. After incubation at $37^{\circ} \mathrm{C}$ for $48 \mathrm{~h}$, the supernatants were collected as a source of secreted NO which was quantitated by determining the nitrite concentration using the Griess assay [equal volumes of A) $1 \%$ sulfanilamide, and B) $0.1 \%$ naphthylethylendiamine dihydrochloride $/ 3 \% \mathrm{H}_{3} \mathrm{PO}_{4}$ ] [19]. For this, aliquots of $100 \mu \mathrm{L}$ of the supernatants were mixed with $100 \mu \mathrm{L}$ of Griess reagent. After $5 \mathrm{~min}$ at room temperature, the absorbance was measured at $550 \mathrm{~nm}$ using an ELISA reader. Cells activated with rIFN- $\gamma$ (100 Units/mL) (Genentech) plus LPS (10 ng/mL) (Salmonella friedenau, kindly provided by O. Holst, Forschungsinstitut Borstel, Germany) at $37^{\circ} \mathrm{C}$ for $12 \mathrm{~h}$ served as a positive control, and nontreated cells were used as a negative control. The experiments were performed in duplicate and repeated three times in independent experiments. Results are given relative to positive control values, set to $100 \%$.
In a modified procedure, cells were incubated with resveratrol for $48 \mathrm{~h}$ and post-treated with $\mathrm{IFN}-\gamma(100 \mathrm{U} / \mathrm{mL})$ plus LPS $(10 \mathrm{ng} /$ $\mathrm{mL}$ ). After incubating for $12 \mathrm{~h}$, NO levels were measured as described above.

In parallel, cells were first activated with rIFN- $\gamma(100 \mathrm{U} / \mathrm{mL})$ plus LPS $(10 \mathrm{ng} / \mathrm{mL})$ for $5 \mathrm{~h}$ followed by adding resveratrol. After $24 \mathrm{~h}$ incubation, the NO levels relative to that of the positive control were determined (vide supra).

\section{NO-scavenging activity}

The scavenging effects of resveratrol on NO were measured using SNP as an NO donor. SNP $(4.5 \mu \mathrm{M})$ was incubated for $3 \mathrm{~h}$ alone or in combination with different concentrations of resveratrol. Incubations were performed in daylight at room temperature, and nitrite levels were determined after $3 \mathrm{~h}$ by Griess reaction.

\section{Western blotting}

J774-G8 cells were exposed to vehicle control or resveratrol for $48 \mathrm{~h}$. Supernatants were removed and cells stimulated with $10 \mathrm{ng} / \mathrm{mL}$ LPS (Salmonella friedenau) and $100 \mathrm{U} / \mathrm{mL}$ murine rIFN$\gamma$ for an additional $12 \mathrm{~h}$. Untreated cells in fresh medium (R5) served as a negative control.

Cell lysates [lysis buffer: $10 \mathrm{mM}$ Tris (pH 7,2; Roth), $150 \mathrm{mM} \mathrm{NaCl}$ (Merck), 1\% Triton $^{\circledR}$ X-100 (Merck), 1\% Na-desoxycholat (Sigma); protease inhibitor mix, complete EDTA-free (Roche)] were ultrasonicated, and the homogenate was centrifuged at $9600 \times \mathrm{g}$ for $10 \mathrm{~min}$ at $4{ }^{\circ} \mathrm{C}$ to remove insoluble material. Protein concentrations were determined with the bicinchoninic acid (BCA) protein assay reagent (Pierce) using BSA as a standard.

Equal amounts of macrophage-lysate proteins (20 $\mu \mathrm{g}$,) for iNOS were separated on 10\% SDS- polyacrylamide gels (precast gels, peqlab). A PageRuler Plus Prestained Protein Ladder (Fermentas, Thermo Scientific) was used as a size reference. Proteins were transferred to pure nitrocellulose membranes (Whatman Pro$\left.\operatorname{tran}^{\circledR}\right)$. The membranes were incubated in blocking buffer, $5 \%$ milk powder (Sigma-Aldrich) in PBS (phosphate buffer saline), at room temperature for $1 \mathrm{~h}$ with agitation. The membranes were then incubated with rabbit iNOS polyclonal antibody (rabbit polyclonal to iNOS; Abcam, 1:200 in blocking buffer) and rabbit $\beta$-actin polyclonal antibody (rabbit polyclonal to beta-actin; $1: 2000 ;$ Abcam) overnight. Membranes were washed twice with PBS-T $(0.05 \%)$ and incubated sequentially with blocking puffer and HRP-conjugated goat anti-rabbit IgG (H\&L) at a dilution of $1: 3000$ ( $5 \%$ milk powder in PBS). Immunodetection was performed using an enhanced chemiluminescence detection kit (Amersham ECL Prime Western Blotting Detection System; GE). Expression levels of the $\beta$-actin protein were used for standardization.

\section{Statistical analysis}

Data are expressed as the mean \pm standard deviation (SD) of at least three independent experiments. Statistical analysis was performed by Student's t-test; $\mathrm{p}$ values $<0.05$ were considered to be statistically significant.

\section{Supporting information}

The following are available as Supporting Information: figures of the antileishmanial activity of resveratrol against promastigotes (Fig. 1S); cytotoxic effects of resveratrol on noninfected ВММФ using FACS analysis (Fig.2S); changes in cell morphology of ВММФ upon treatment with resveratrol (Diff-Quick ${ }^{\circledR}$ stain) 
(Fig. 3S); and induction of apoptosis by resveratrol in J774-G8 cells (Fig. 4S).

\section{Results and Discussion}

Leishmania protozoa require an insect vector and a vertebrate host to complete their biological cycle. Within the former, the parasites exist as extracellular, motile flagellates in the gut, while phagocytized promastigotes transform into nonmotile amastigotes and reside in compartments of macrophages and monocytes. Massive amastigote multiplication leads to host cell disruption and release of the intracellular forms to infect newly recruited host cells. Since promastigotes are encountered in the mammalian host only for a very short time after transmission of the insect vector, it is the intracellular amastigote that is of clinical and pharmacological importance. Attention was therefore given to the antiamastigote effects of resveratrol. Having in mind that a difference in antileishmanial activity against the two stages of the parasite may well exist, promastigotes were included in this study.

Using transgenic L. major GFP, resveratrol exhibited pronounced antileishmanial effects on promastigotes but at therapeutically unacceptably high sample ranges. At $45 \mu \mathrm{g} / \mathrm{mL}(196.9 \mu \mathrm{M})$, the GFP signal as a measure of the parasites' viability was significantly reduced by ca. $97 \%$ as assessed by FACS analysis (Fig. 1S). Conspicuously, moderate killing rates (ca. 10\%) were observed at sample concentrations $\leq 35 \mu \mathrm{g} / \mathrm{mL}(\leq 153.3 \mu \mathrm{M})$. This finding may be indicative of a limited tolerance of $L$. major GFP to resveratrol, which appears crucial when establishing a relevant dose effective against the extracellular form. Parallel staining with PI to discriminate viable from dead parasites confirmed the antileishmanial activity profile of resveratrol. Although previous work showed similar antipromastigote activities, the issue of a required minimal concentration has not been documented. The fairly high rationale dose of at least ca. $40 \mu \mathrm{g} / \mathrm{mL}(175 \mu \mathrm{M})$ calls for reliable data about the safety of resveratrol, which is claimed to be generally well tolerated.

Experimental infection of macrophages constitutes a particularly versatile model for assessing selective direct effects of an agent on intracellular pathogens as well as indirect antiparasitic effects via macrophage activation. In our initial work, ВММФ experimentally infected with $L$. major GFP promastigotes were rested for $24 \mathrm{~h}$ at $37^{\circ} \mathrm{C}$ to allow internalized parasites to transform into amastigotes. When infected cells were exposed to resveratrol for an additional $48 \mathrm{~h}$, the resulting GFP signal was reduced in a concentration-dependent manner compared to the non-treated population $\left[\mathrm{IC}_{50}=9.9 \mu \mathrm{g} / \mathrm{mL}(43.6 \mu \mathrm{M})\right]$ (○ Fig. 1). Amphotericin B served as a positive control.

To gain insight into the underlying antileishmanial mode of action, the NO-inducing potential of resveratrol was evaluated. Activated macrophages are known to produce a variety of potentially cytotoxic effector molecules, of which nitric oxide and its congeners represent the most effective microbicidal species against Leishmania parasites $[20,21]$. Aliquots of the culture supernatants were collected for measuring NO concentrations using the Griess assay. Consistent with previous findings, the combination of rIFN- $\gamma$ plus LPS strongly induced NO production (ca. $28 \mu \mathrm{M}$ ) [13]. In contrast, the NO-inducing potential of resveratrol was relatively weak with similar levels noted for noninfected and infected macrophages (ca. $3 \mu \mathrm{M}$ ) (data not shown). This finding suggested that resveratrol did not stimulate the in-

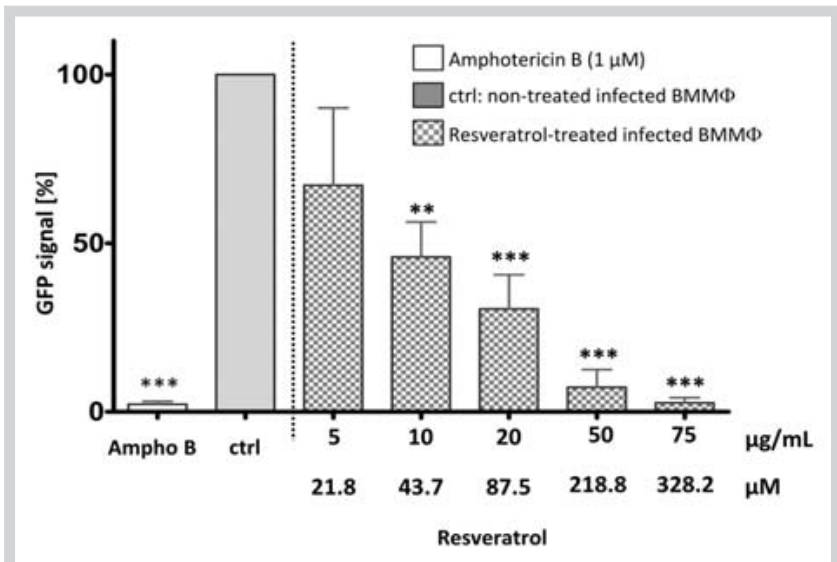

Fig. 1 Antileishmanial activity of resveratrol against infected BMMФ. Loss of GFP signal was assayed by FACS analysis and related to non-treated cells as a control group, defined as $100 \%$. Amphotericin B (1 $\mu \mathrm{M})$ served as a positive control. Exposure of infected BMM $\Phi$ to resveratrol reduced the GFP signal in a concentration-dependent manner. Data are expressed as mean $\pm S D(n=4)$ related to non-treated cells. ${ }^{*}: p<0.05 ;{ }^{* *}: p<0.01 ;{ }^{* * *}$ : $p<0.001$ vs. control (ctrl: cells + medium $+0.2 \%$ DMSO). The vehicle (medium and DMSO, respectively) did not affect the antileishmanial effects (data not shown).

fected macrophages for NO release and that its antileishmanial activity was apparently mediated by a different mode of action. Before investigating alternative antiparasitic mechanisms, it appeared meaningful to focus on NO scavenging and iNOS inhibiting effects of resveratrol to rationalize the low NO levels. That resveratrol is capable of decreasing the NO level in cells has been demonstrated for a range of cell types, including macrophages [22,23], skeletal muscle [24], and cardiomyocytes [25]. However, resveratrol has also been reported to enhance NO production and to modify expression of NOS isoforms [26-28]. In a first set of experiments, NO was generated in a cell-free system using sodium nitroprusside as an NO donor and measured spectrophotometrically. Addition of resveratrol moderately decreased the produced NO level in a concentration-dependent manner to ca. $65 \%$ of the control value in test concentrations $\geq 30 \mu \mathrm{g} / \mathrm{mL}$ (data not shown), indicating that direct NO scavenging effects played a minor role in reducing $\mathrm{NO}$ production.

Next, J774-G8 cell cultures stimulated with rIFN- $\gamma$ plus LPS were incubated with resveratrol. As shown in $\odot$ Fig. 2, NO production was significantly decreased by the presence of resveratrol in a concentration-dependent manner $\left(\mathrm{IC}_{50}=5.2 \mu \mathrm{g} / \mathrm{mL} ; 22.8 \mu \mathrm{M}\right)$, indicating inhibition of iNOS mRNA/protein expression or enzyme activity. This finding was consistent with similar reports on a range of cell types [22-25].

In a modified procedure, J774-G8 cell cultures were pretreated with resveratrol for $48 \mathrm{~h}$, followed by incubating with the known macrophage-stimulating agents rIFN- $\gamma$ and LPS. Again, the release of NO was similarly reduced in a concentration-dependent manner (data not shown). Accordingly, the inhibition of NO production by resveratrol may largely be ascribed to inhibition of iNOS.

A Western blot-based protocol was subsequently employed to examine the expression of iNOS at the protein level. Results showed that J774-G8 cells treated with resveratrol exhibited a concentration-dependent decrease in the levels of iNOS when compared with the control levels ( $\bullet$ Fig. 3). This finding was consistent with 


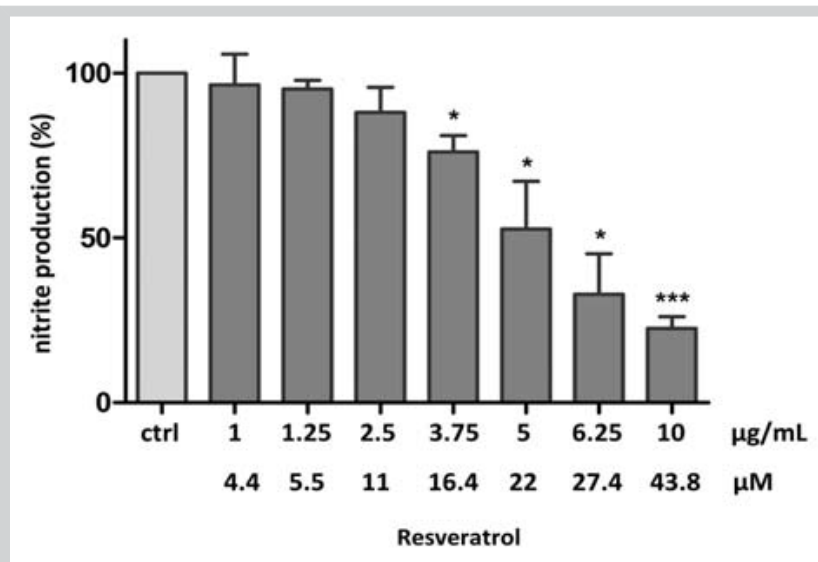

Fig. 2 NO production by activated J774-G8 macrophages related to cells stimulated with rIFN- $\gamma(100 \mathrm{U} / \mathrm{mL})$ plus LPS $(10 \mathrm{ng} / \mathrm{mL})$ as a positive control, defined as $100 \%$ (Griess reagent). Cells were incubated with resveratrol for $48 \mathrm{~h}$ and subsequently stimulated with rIFN- $y(100 \mathrm{U} / \mathrm{mL})$ plus LPS $(10 \mathrm{ng} /$ $\mathrm{mL})$ for $12 \mathrm{~h}$. Data are expressed as mean $\pm \mathrm{SD}(\mathrm{n}=3) ;{ }^{*}: \mathrm{p}<0.05$ and ${ }^{* * *}$ : $\mathrm{p}<0.001$ compared to the control group (ctrl: rIFN- $/$ /LPS-stimulated cells + medium $+0.2 \% \mathrm{DMSO}$ ). The vehicle (medium and DMSO, respectively) did not affect the NO levels (data not shown).

observed reduced NO production upon resveratrol treatment (vide supra) and supported the conjecture that resveratrol inhibited NO production primarily by suppression of iNOS expression. Nonstimulated cells expressed very low levels of iNOS protein. Resveratrol is reported to be generally well tolerated, and only minor side effects have been observed in short-term studies. Based on animal experiments, toxicological effects were evident at high doses and from long-term administration [29]. Insufficient clinical studies and lacking data on the toxicity of long-term intake of resveratrol in humans reflect inadequate scientific evidence for the safety of resveratrol in medical practice. Adverse effects are one of the most critical pharmacological features. Accordingly, the clinical relevance of intracellularly persisting Leishmania amastigotes prompted special attention to the evaluation of possible cytotoxic effects of resveratrol on macrophages as host cells.

In a first set of experiments, the effect of resveratrol on the viability of ВMMФ host cells was tested using the MTT assay and related to untreated cells, defined as $100 \%$. Cytotoxicity increased in a concentration-dependent manner, indicating an $\mathrm{IC}_{50}$ value of $16.3 \mu \mathrm{g} / \mathrm{mL}(71.6 \mu \mathrm{M})$ (๑ Fig. 4). This finding contrasts with the reported absence of any toxic effects of resveratrol up to $45 \mu \mathrm{g} / \mathrm{mL}(196.9 \mu \mathrm{M})$ [12].

An additional set of FACS-based assays was therefore performed on sented cytotoxicity of resveratrol. Again, cytotoxicity significantly enhanced with increasing concentrations, as evident from the number of PI-positive events (Fig. 2S). The complementary assessment of cytotoxic effects carried out at single cell levels reaffirmed the toxic potential of resveratrol observed by means of the MTT assay. Importantly, cell cytotoxicity was negligible $(\geq 0.5 \%)$ in all untreated incubations as assessed by PI staining. Since microscopic studies were exclusively used in previous work [12], we embarked on a similar protocol to further verify our results. Diff-Quik ${ }^{\circledR}$ stain revealed dramatic changes in the morphology of both non-infected and infected cells (Fig. 3S), thus reconfirming a cytotoxic potential of resveratrol as assessed in the MTT

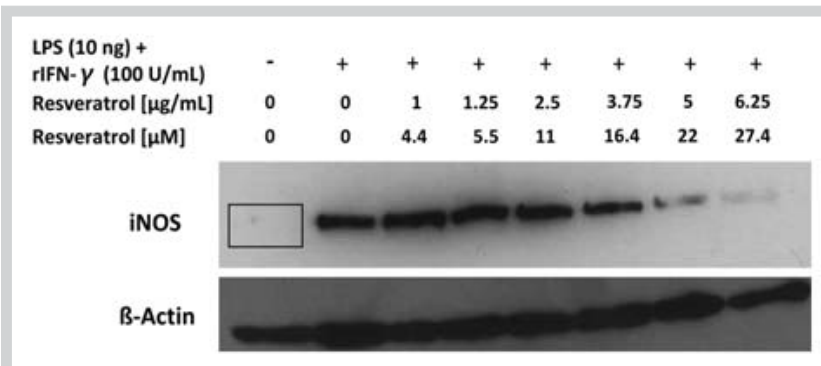

Fig. 3 Effects of resveratrol on rIFN- $\gamma /$ LPS-induced expression of iNOS in J774-G8 cells. Cells were treated with resveratrol for $48 \mathrm{~h}$ and subsequently incubated with rIFN- $y(100 \mathrm{U} / \mathrm{mL}) / \mathrm{LPS}(10 \mathrm{ng} / \mathrm{mL})$ for $12 \mathrm{~h}$. Total protein was subjected to SDS-PAGE followed by Western blotting, using $\beta$-actin for standardization. One of three experiments with similar results is shown.

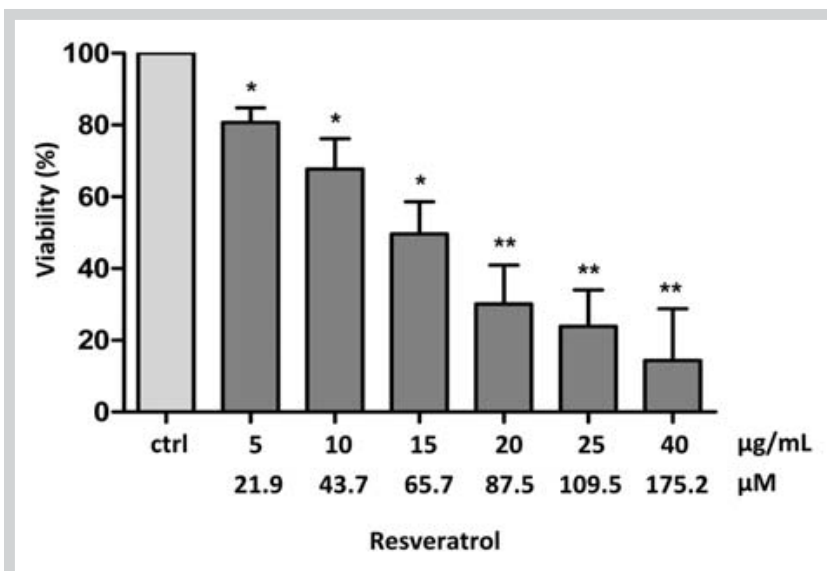

Fig. 4 Cytotoxic effects of resveratrol on noninfected BMMФ using the MTT assay. Cell cytotoxicity increased in a concentration dependent manner. The results are shown relative to non-treated cells (negative control), defined as $100 \%$. Data are expressed as mean \pm SD $(n=3) ;{ }^{*}$ : $p<0.05$ and ${ }^{* * *}: \mathrm{p}<0.001$ compared to the control group (ctrl: cells + medium $+0.2 \%$ DMSO). The vehicle (medium and DMSO, respectively) did not affect cell viability (data not shown).

assay. Cells clearly displayed highly condensed pyknotic nuclei, and showed more vacuoles and disintegrity of cell membranes. These morphological changes were less evident in noninfected compared with infected cells. Infection per se may therefore have some impact on the cell integrity. Due to the absence of any image documentation in the previous paper [12], the conflicting results cannot satisfactorily be explained.

Finally, differences in the susceptibility of host cells to resveratrol represent a major parameter to provide a clue for the observed discrepancy in cell toxicity. ВMMФ were used in the current experiments, while J774 cultures have been included in the previous study. The panel of cell viability assays including the MTT assay ( $\bullet$ Fig. 5), FACS measurements ( $\bullet$ Fig. $\mathbf{6}$ ), and microscopic studies (Fig. 4S) was therefore extended to J774-G8 macrophages. The pictures that emerged from examining the cytotoxic $\left[\mathrm{IC}_{50}=24.5 \mu \mathrm{g} / \mathrm{mL}(107.7 \mu \mathrm{M})\right]$ and antileishmanial effects of resveratrol $[24.8 \mu \mathrm{g} / \mathrm{mL}(108.6 \mu \mathrm{M})]$ on noninfected and infected J774-G8 host cells were very similar (selectivity index $\mathrm{SI}_{\text {cytotox/ }}$ antileishmanial=1). Results are exemplarily presented for FACS showing the loss of the GFP signal as a measure of parasite viability and cytotoxic effects on host cells after PI staining ( $\mathbf{0}$ Fig. $\mathbf{6}$ ) 


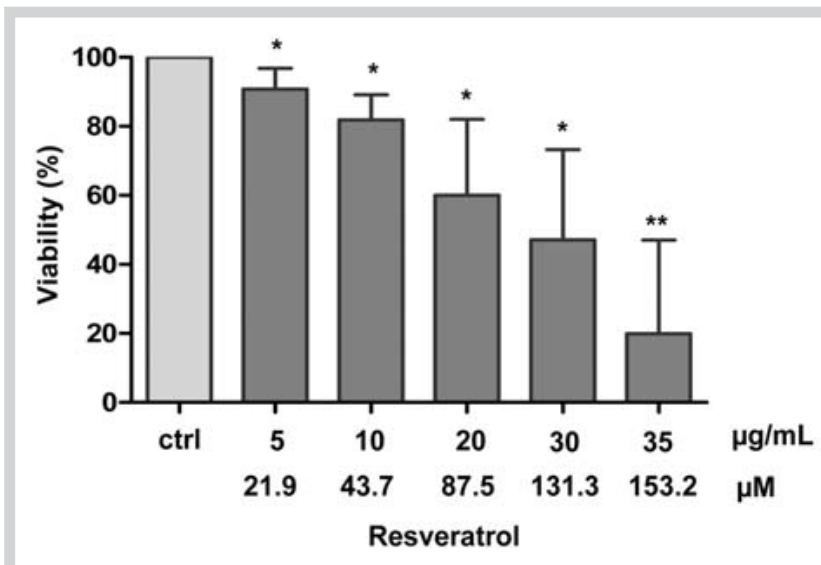

Fig. 5 Cytotoxic effects of resveratrol on noninfected J774-G8 cells as assessed by MTT. The results are shown relative to non-treated cells (negative control), defined as $100 \%$. Data are expressed as mean \pm SD $(n=3)$; ${ }^{*} \mathrm{p}<0.05$ and ${ }^{* * *} \mathrm{p}<0.001$ compared to the control group (ctrl: cells + medium + 0.2\% DMSO). The vehicle (medium and DMSO, respectively) did not affect cell viability (data not shown).

and changes in cell morphology (Fig 4S). This finding clearly excluded any dependency of cytotoxic effects on the kind of cells, at least for ВММФ and J774-G8.

In conclusion, the claimed antileishmanial activity of resveratrol appears to be strongly associated with cytotoxic effects on host cells rather than with antiparasitic properties ( $\mathrm{SI}=1-1.6)$, taking into account the ineffective NO-inducing potential of resveratrol and induction of apoptosis in noninfected macrophages. MTT evaluation, FACS analysis, and microscopic examinations showed similar cytotoxic effects of resveratrol on noninfected J774-G8 and $B M M \Phi$, respectively, thus rendering resveratrol less suitable as an antileishmanial agent. Having in mind that J774-G8 is a mu- rine macrophage-like cancer cell line, the observed pronounced cytotoxic effects may be seen in line with the accumulating evidence for anticancer/chemopreventive activities of resveratrol [30]. Tolerability may well vary from tissue to tissue, and adverse effects occur somewhere in the human body. Clinical trials are therefore needed to evaluate the overall safety more faithfully than conventional in vitro experiments. Although this work demonstrates cytotoxic effects of resveratrol on macrophages under the experimental conditions, if and to what extent these immune cells are affected in vivo remains to be evaluated.

\section{Acknowledgements}

$\nabla$

Thanks are due to Dr. A.F. Kiderlen, Robert Koch-Institut, Berlin, Germany, for hosting I.K. Lucas in his research unit (FG 16) and facilitating the antileishmanial studies. The authors also express their appreciation to Mrs. U. Laube for skilled technical assistance.

\section{Conflict of Interest \\ $\nabla$}

The authors declare none.

\section{References}

1 Maier WA, Grunewald J, Habedank B, Hartelt K, Kampen H, Kimmig P, Naucke T, Oehme R, Vollmer A, Schöler A, Schmitt C. Possible effects of climatic changes on the distribution of arthropod (vector)-borne infectious diseases and human parasites in Germany. UFOPLAN 20061 218/ 11. Climate Change 2003: 05/03 (ISSN 1611 8855)

2 Balana-Fouce R, Reguera RM, Cubria JC, Ordonez D. The pharmacology of leishmaniasis. Gen Pharmacol 1998; 30: 435-443

3 Akendengue B, Ngou-Milama E, Laurens A, Hocquemiller R. Recent advances in the fight against leishmaniasis with natural products. Parasite 1999; 6: 3-8

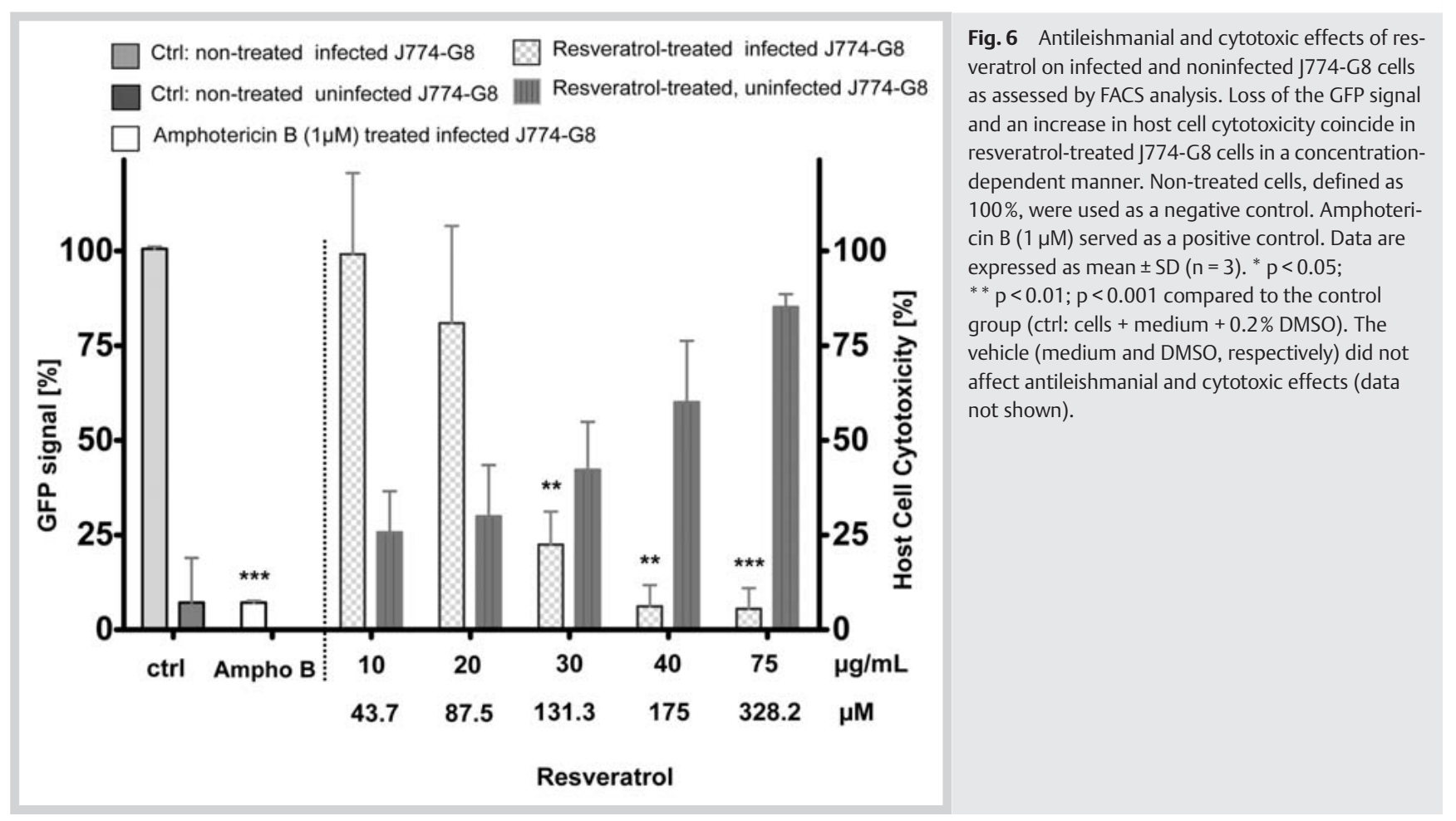


4 Corona MC, Croft SL, Phillipson JD. Natural products as sources of antiprotozoal drugs. Curr Opin Antiinfect Investig Drugs 2000; 2: 47-62

5 Chan-Bacab MJ, Peña-Rodríguez LM. Plant natural products with leishmanicidal activity. Nat Prod Rep 2001; 18: 674-688

6 Kolodziej H, Kiderlen AF. Antileishmanial activity and immune modulatory effects of tannins and related compounds on Leishmania parasitized RAW 264.7 cells. Phytochemistry 2005; 66: 2056-2071

7 Kedzierski L, Sakthianandeswaren A, Curtis JM, Andrews PC, Junk PC, Kedzierska $K$. Leishmaniasis: current treatment and prospects for new drugs and vaccines. Curr Med Chem 2009; 16: 599-614

8 Baur JA, Sinclair DA. Therapeutic potential of resveratrol: the in vivo evidence. Nat Rev 2006; 5: 493-506

9 Weng CJ, Wu CF, Huang HW, Wu CH, Ho CT, Yen GC. Evaluation of antiinvasion effect of resveratrol and related methoxy analogues on human hepatocarcinoma cells. J Agric Food Chem 2010; 58: 2886-2894

10 Turan B, Tuncay E, Vassort G. Resveratrol and diabetic cardiac function: focus on recent in vitro and in vivo studies. J Bioenerg Biomembr 2012; 44: $281-296$

$11 \mathrm{Kim}$ MH, Yoo DS, Lee SY. The TRIF/TBK1/IRF-3 activation pathway is the primary inhibitory target of resveratrol, contributing to its broad-spectrum anti-inflammatory effects. Pharmazie 2011; 66: 293-300

12 Kedzierski L, Curtis JM, Kaminska M, Jodynis-Liebert J, Murias M. In vitro antileishmanial activity of resveratrol and its hydroxylated analogues against Leishmania major promastigotes and amastigotes. Parasitol Res 2007; 120: 91-97

13 Kram D, Thäle C, Kolodziej H, Kiderlen AF. Intracellular parasite kill: flow cytometry and NO detection for rapid discrimination between antileishmanial activity and macrophage activation. J Immunol Methods 2008; 333: 79-88

14 Ha DS, Schwarz JK, Turco SJ, Beverly SM. Use of the green fluorescent protein as a marker in transfected Leishmania. Mol Biochem Parasitol 1996; 77: 57-64

15 Berens L, Marr JJ. An easily prepared defined medium for cultivation of Leishmania donovani promastigotes. J Parasitol 1978; 64: 160

16 Kiderlen AF, Kaye PM. A modified colorimetric assay of macrophage activation for intracellular cytotoxicity against Leishmania parasites. J Immunol Methods 1990; 127: 11-18

17 Kedzierski L, Montgomery J, Bullen D, Curtis JM, Gardiner E, Jimenez-Ruiz A, Handman E. A leucine-rich repeat motif of Leishmania parasite surface antigen 2 binds to macrophages through the complement receptor 3. J Immunol 2004; 172: 4902-4906
18 Mosman TJ. Rapid colorimetric assay for cellular growth and survival: application to proliferation and cytotoxic assays. J Immunol Methods 1983; 65: 55-63

19 Ding AH, Nathan CF, Stuehr DJ. Release of reactive nitrogen intermediates and reactive oxygen intermediates from mouse peritoneal macrophages. Comparison of activating cytokines and evidence for independent production. J Immunol 1988; 141: 2407-2412

20 Green SJ, Melzer MS, Hibbs Jr. JB, Nacy CA. Activated macrophages destroy intracellular Leishmania major amastigotes by an L-arginine-dependent killing mechanism. J Immunol 1990; 144: 278-283

21 Lemesre JL, Sereno D, Daulouède S, Veyret B, Brajon N, Vincendeau P. Leishmania spp.: nitric oxide-mediated metabolic inhibition of promastigote and axenically grown amastigote form. Exp Parasitol 1997; 86: 58-68

22 Ma ZH, Ma QY, Wang LC, Sha HC, Wu SL, Zhang M. Effect of resveratrol on peritoneal macrophages in rats with severe acute pancreatitis. Inflamm Res 2005; 54: 522-527

23 Meng XL, Yang JY, Chen GL, Wang LH, Zhang LJ, Wang S, Li J, Wu CF. Effects of resveratrol and its derivatives on lipopolysaccharide-induced microglial activation and their structure-activity relationships. Chem Biol Interact 2008; 174: 51-59

24 Centeno-Baez C, Dallaire P, Marette A. Resveratrol inhibition of inducible nitric oxide synthase in skeletal muscle involves AMPK but not SIRT1. Am J Physiol Endocrinol Metab 2011; 301: E922-E930

25 Wang S, Qian Y, Gong D, Zhang Y, Fan Y. Resveratrol attenuates acute hypoxic injury in cardiomyocytes: correlation with inhibition of iNOS-NO signalling pathway. Eur J Pharm Sci 2011; 44: 416-421

$26 \mathrm{Kim}$ T, Suh ES. Retinal protective effects of resveratrol via modulation of nitric oxide synthase on oxygen-induced retinopathy. Korean J Opthalmol 2012; 24: 108-118

27 Hattori R, Otani H, Maulik N, Das DK. Pharmacological preconditioning with resveratrol: role of nitric oxide. Am J Physiol Heart Circ Physiol 2002; 282: H1988-H1995

28 Wallerath T, Deckert G, Ternes T, Anderson H, Li H, Witte K, Förstermann $U$. Resveratrol, a polyphenolic phytoalexin present in red wine, enhances expression and activity of endothelial nitric oxide synthase. Circulation 2002; 106: 1652-1658

29 Vang O, Ahmad N, Baile CA, Baur JA, Brown K. What is new for an old molecule? Systematic review and recommendations on the use of resveratrol. PLoS ONE 2011; 6: 1-11

30 Bhat KPL, Kosmeder JW II, Pezzuto JM. Biological effects of resveratrol. Antioxid Redox Signal 2001; 3: 1041-1064 